Jurnal Lakon, 5 (1) 2016

(30-44)

\title{
REALISME MAGIS DALAM NOVEL SIMPLE MIRACLES DOA DAN ARWAH KARYA AYU UTAMI
}

Magic Realism in Ayu Utami's Simple Miracle Doa dan Arwah Novel

\section{SANDRA WHILLA MULIA}

\author{
Program Studi Magister Kajian Sastra dan Budaya \\ Fakultas Ilmu Budaya Universitas Airlangga \\ Jl. Dharmawangsa Dalam Selatan, Surabaya \\ e-mail: sandra_whilla@yahoo.co.id
}

\begin{abstract}
This study are intend to reach some goals. First, this aimed to uncover the magic realism which is narrated in Ayu Utami's novel, entitled Simple Miracle Doa Dan Arwah. Second, this study aimed to discover socio cultural context which form the background of the emerging of magic realism of narrative in Ayu Utami's novel entitled Simple Miracle Doa dan Arwah. This research utilizes magic realism narrative theory on the book Ordinary Enchantments Magical Realism and Remystifiction of Narratives written by Wendy B. Faris (2004). This is a qualitative study which employed textual analysis to analyze the obtained data. The results of this study were magic realism which was narrated in the novel were not only loaded by the characteristics of Faris' magic realism by showing the exquisite existence of myth in this modern era, but also written to be in charge of bracing and reorganizing people's believe in Javanese myth. Socio cultural context which form the background of the emerging of this novel was Javanese culture that still exist in this modern era. This was also added by the comeback of traditional ambience which made its existence popular nowadays. From the analysis this had emerged two issues, social issues and signification issues. The emerging social issues are the Javanese culture in which the people tend to fancy mystics. These mystics are related to ghosts. In addition, the other issue is about acculturation of religions in Java Island. Besides the issues, the signification obtained were: (1) Javanese will always hold their believe in ghost; (2) in Java, shaman and spirits or ghost are correlated to the second alternative to realize dreams; (3) shaman identity is identical with someone who has an ability to see and communicate with spirits or ghosts; (4) there is a believe that spirits and ghosts are everywhere; (5) Javanese believe that every dead person will soon become spirits and ghosts and they will eternally live around them; (6) atheist will rarely be seen in Java; (7) religions in Java Island will always blend themselves with the culture.
\end{abstract}

Keywords: Acculturation Of Religions, Ghosts, Javanese Culture, Magic Realism, Simple Miracles Doa dan Arwah

Abstrak: Penelitian yang berjudul "Realisme magis dalam novel Simple Miracles Daa dan Arwah Karya Ayu Utami" ini bertujuan yang pertama untuk mengungkapkan realisme magis yang ternarasikan dalam novel Simple Miracles Doa dan Arwah karya Ayu Utami. Kedua, menemukan konteks sosial budaya yang melatarbelakangi munculnya narasi realisme magis dalam novel Simple Miracles Doa dan Arwah karya Ayu Utami. Penelitian ini memanfaatkan teori naratif realisme magis Faris dalam bukunya yang berjudul Ordinary Enchantments Magical Realism and Remystifiction of Narratives (2004). Penelitian ini termasuk penelitian kualitatif dengan teknik analisis data menggunakan tekstual analisis atau analisis teks. Hasil yang didapat dalam penelitian ini adalah, realisme magis yang ternarasikan dalam novel Ayu Utami tidak hanya sarat dengan karakteristik realisme magis Faris dengan memperlihatkan eksistensi mitos di era modern, tetapi juga bertugas

Jurnal Lakon: Kajian Sastra dan Budaya

e-ISSN: 2527-4899; p-ISSN 2252-8954 
mengukuhkan suatu kepercayaan mengenai mitos di Jawa serta merombaknya. Konteks sosial budaya yang melatarbelakangi munculnya novel karya Ayu Utami disebabkan oleh kebudayaan Jawa yang sampai saat ini masih eksis serta kembali populernya hal-hal yang berbau tradisional dalam era modern ini. Dari hasil analisis tersebut memunculkan dua isu sosial dan pemaknaan. Isu sosial yang muncul yakni isu mengenai kesukaan orang Jawa pada hal-hal mistis yang berkaitan dengan makhluk halus serta isu mengenai akulturasi budaya Jawa dengan agama-agama di Jawa. Makna yang diperoleh antara lain: (1) orang Jawa akan selalu percaya pada hal-hal mistis yang berkaitan dengan makhluk halus; (2) di Jawa, dukun dan makhluk halus adalah alternatif kedua untuk mewujudkan cita-cita; (3) identitas dukun identik dengan seorang yang memiliki kemampuan melihat dan berkomunikasi dengan makhluk halus; (4) adanya kepercayaan bahwa makhluk halus itu ada di mana-mana; (5)orang Jawa percaya bahwa setiap orang meninggal akan menjadi roh yang tetap hidup di sekeliling mereka; (6) orang ateis jarang ditemui di Jawa; (7) Agama-agama yang ada di Jawa selalu menyesuaikan diri dengan kebudayaan Jawa.

Kata-kata Kunci: Akulturasi Agama, Budaya Jawa, Makhluk Halus, Realisme Magis, Simple Miracles Doa dan Arwah

\section{PENDAHULUAN}

Orang Jawa (Javanese) merupakan orang-orang yang mendukung dan menghayati budaya Jawa yang tersebar di daerah asal kebudayaan Jawa, Jawa Tengah dan Jawa Timur, di Cirebon Jawa Barat, di banyak kepulauan di Indonesia bahkan di luar negeri (Setyodarmodjo, 2007:72). Hardjowirogo (1984:7), menambahkan bahwa semua orang Jawa itu berbudaya satu. Orang Jawa berpikir dan berperasaan seperti moyang mereka di Jawa Tengah, dengan kota Solo dan Yogya sebagai pusatpusat kebudayaan, dari Yogya dan Solo itulah aliran kejawen muncul dan berkembang di seluruh tanah Jawa (Sudiantara, 1998:5).

Sosok orang Jawa dengan berbagai karakteristik kehidupannya tersebut tak jarang diangkat dalam karya sastra. Seperti yang telah diketahui bahwa sastra merupakan penggambaran kehidupan yang dituangkan melalui media tulisan. Terdapat hubungan yang erat antara sastra dan kehidupan karena fungsi sosial sastra adalah bagaimana ia melibatkan dirinya di tengah-tengah kehidupan masyarakat
(Semi, 1989:56). Karya sastra yang mengangkat kehidupan orang Jawa diperlihatkan dalam novel Simple Miracles Doa dan Arwah karya Ayu Utami. Novel ini bercerita tentang kehidupan satu keluarga Jawa yang tinggal di Bogor, namun masih mengamalkan kepercayaan atau tradisi yang berkaitan dengan mitos di Jawa. Salah satunya masih memiliki kepercayaan pada hal-hal mistik sesuai karakteristik kehidupan orang Jawa, yakni percaya terhadap makhluk halus serta hal-hal yang bersifat takhyul. Dalam novel Simple Miracles Doa dan Arwah (selanjutnya disingkat: SMDA) diperlihatkan bahwa makhluk halus yang dihadirkan merupakan mahkluk halus yang melegenda di Jawa (misalnya: pocong dan kuntilanak). Melalui novel Ayu Utami itulah dapat diketahui bahwa karya sastra tidak hanya berkisah tentang hal-hal yang berkaitan dengan keseharian makhluk hidup yang sifatnya terlihat, tetapi juga berkisah tentang halhal sifatnya tak terlihat yang berhubungan dengan adanya kepercayaan mengenai halhal magis, takhyul, serta bersifat irrasional yang berkaitan dengan dunia lain yang ditinggali makhluk halus (baik dari

Jurnal Lakon: Kajian Sastra dan Budaya

e-ISSN: 2527-4899; p-ISSN 2252-8954 
golongan memedi maupun arwah penasaran).

Ada hal menarik dari isi novel karya Ayu Utami ini, yakni sesuatu yang memiliki citra sakral, tradisional, serta segala sesuatu yang lebih mengarah terhadap halhal yang berada di luar logika manusia (dalam budaya Jawa) dihadirkan pada era modern seperti saat ini. Fenomena kemunculan karya SMDA ini identik dengan karya sastra realisme magis. Karya sastra realisme magis adalah karya sastra yang menghadirkan kembali segala citra dan pengertian yang bersifat magis, mistis, ataupun "irrasional" yang bersumber dari cerita mitologi, dongeng, legenda yang hidup secara tradisional yang dihadirkan dalam sebuah kesusastraan modern diindikasikan sebagai karya realisme magis (Faris, 1995). Realisme magis muncul di kesusatraan Indonesia tahun 1990-an, arus realisme magis sebagai paham kesastraan global mulai masuk dan memperlihatkan pengaruhnya pada sejumlah karya sastra Indonesia. Sebelum karya Ayu Utami ini, sudah ada pengarang lain yang menulis cerita fiksi bergenre realisme magis, misalnya Eka Kurniawan dan Seno Gumira Ajidarma. Menurut Alex (Kompas, edisi 30 November 2003), dalam kesusatraan Indonesia Seno Gumira Ajidarma dengan cerpennya "Misteri Kota Ningi", Eka Kurniawan dengan novelnya "Cantik Itu Luka" menunjukkan pengaruh tersebut dalam prosa Indonesia. Salah satu karakter realisme magis yakni menghadirkan kembali segala citra dan pengertian yang bersifat magis, mistis, ataupun "irrasional" yang bersumber dari karya-karya mitologis, dongeng, legenda yang hidup secara tradisional dalam masyarakat-masyarakat etnik di Indonesia dalam karya sastra mutakhir dapat menjadi strategi melihat kecenderungan baru tersebut.
Meskipun tiga pengarang ini hidup di era yang sama, namun karya Eka Kurniawan dan Seno Gumira Ajidarma berbeda dengan karya Ayu Utami. Karya Eka dan Seno lebih menitikberatkan mitosmitos yang berkaitan dengan legenda pada masa lampau dengan setting pada zaman kolonial dan sesudah masa kolonial sedangkan karya Ayu Utami ini menghadirkan cerita yang didominasi mitos (kepercayaan) serta ritual yang semuanya itu berhubungan dengan makhluk halus dengan setting zaman modern. Mitos (kepercayaan) serta ritual yang hadir dalam cerita novel SMDA pun sangat familiar di telinga orang Jawa. Secara tidak langsung kehadiran novel SMDA ini bukan hanya sebagai bacaan hiburan, namun juga mengkomunikasikan sesuatu misalnya memperlihatkan isu-isu sosial atau memperlihatkan eksistensi mitos/ kepercayaan serta tradisi (budaya Jawa) pada era saat ini. Seperti yang diungkapkan Junus (1981:93), bahwa kehadiran teks sastra atau novel yang menyuarakan, menghadirkan, dan mempersoalkan kepercayaan mengenai hal-hal magis seperti mitos, pasti memiliki maksud tertentu misalnya bertugas

mengukuhkan suatu kepercayaan mengenai mitos tertentu, atau mungkin bertugas merombak, membebaskan, memodifikasi, bahkan untuk menentangnya.

Berkaca dari penjelasan tersebut ada hal yang mendorong peneliti untuk mengungkapkan motif di balik munculnya karya Simple Miracles Doa dan Arwah yang menghadirkan mitos atau kepercayaan yang berasal dari masa lampau ke masa kini. Apakah karya ini dihadirkan untuk dijadikan sebagai dokumen sosial budaya yang mencatat kenyataan budaya suatu masyarakat pada masa tertentu seperti yang dijelaskan oleh Junus (1986), bahwa 
fungsi karya sastra juga sebagai dokumen sosial budaya yang menjelaskan budaya atau keadaan masyarakat pada masa tertentu, ataukah bermaksud memperlihatkan bahwa semodern apapun masyarakat Jawa tetap tak dapat terpisahkan dari kepercayaan-kepercayaan magis tersebut.

Berdasarkan problematik tersebut yang mendorong peneliti memilih novel Simple Miracles Doa dan Arwah sebagai objek penelitian ini. Selain itu, dari berbagai novel karangan Ayu Utami (Seperti: Dwilogi Saman dan Larung, Trilogi Si Parasit Lajang-Cerita Cinta Enrico- Pengakuan Eks Parasit Lajang, serta Bilangan Fu dan Seri Bilangan Fu (Manjali dan Cakrabirawa, Lalita, Maya)), baru kali ini menceritakan kisah yang isinya didominasi adanya kepercayaan mengenai makhluk halus pada benak orang Jawa yang diperlihatkan melalui kehidupan satu keluarga Jawa yang tinggal di Bogor.

Novel ini adalah novel seri spiritualisme kritis (Utami, 2014:173). Menurut Utami (2014:176)

Spiritualisme kritis adalah sikap terbuka pada yang spiritual tanpa mengkhianati nalar kritis. Terbuka di sini adalah terbuka pada dunia spirit, arwah, mitos, maupun kepercayaan pada hal-hal mistis. Novel seri ini sebagian besar isinya memuat kisah yang berkaitan dengan hal-hal magis (mitos dan kepercayaan-kepercayaan terhadap makhluk halus) yang berkembang dalam masyarakat Jawa. Tidak seperti karya-karya sebelumnya yang meski menyajikan beberapa mitos dan legenda, tetapi lebih didominasi tentang gambaran manusia Indonesia dalam bentang sejarah yang cukup panjang (1900-an hingga era 2000an) atau bisa disebut sebagai kisah yang berlatar politik Indonesia dari era
Soekarno, Soeharto, hingga reformasi seperti: rezim militer, orde baru, peristiwa politik, feminisme, serta asmara (hubungan lelaki dan perempuan). Ayu

Utami menghadirkan novel ini dengan judul Simple Miracles Doa dan Arwah,yakni judul yang tampak menggunakan gabungan bahasa Inggris dan Indonesia. Dalam novelnya doa dan arwah dihadirkan sebagai sesuatu yang menurutnya simple yang ada dalam kehidupan sehari-hari orang Jawa, namun sesuatu yang bernilai "simple" tersebut bercitra ajaib (Utami, 2014).

Penelitian yang membahas tentang karya sastra dengan konsep realisme magis pernah dilakukan oleh beberapa peneliti. Kadir (2014), yang membahas "Kadar Realisme Magis dalam Novel Perempuan Poppo Karya Dul Abdul Rahman"; Ferdiyanto (2014) yang membahas "Realisme Magis dalam Novel Beloved Karya Toni Morrison"; serta Tom (1999) yang membahas tentang "Magical realism, freedom, and control in Garcia Marquez, Millhauser, and Winterson". Dari ketiga penelitian tersebut semua mengusung realisme magis untuk menganalisis teks sastra. Namun, penelitian ini berbeda dengan penelitian tersebut. Pertama, penelitian ini memilih objek yang berbeda dengan ketiga penelitian di atas. Kedua, belum ada yang membahas novel yang mengangkat kisah tentang hal magis di Jawa yang analisisnya menggunakan realisme magis seperti di atas. Sebenarnya penelitian menggunakan objek novel Ayu Utami sudah banyak yang dilakukan, namun kebanyakan hanya menyoroti gender, feminism, sex, atau rezim politik, seperti penelitian yang dilakukan Purwanti (2009) dari UNS Surakarta yang melakukan penelitian dengan judul "Novel Saman dan Larung Karya Ayu Utami dalam Perspektif Gender". 
Penelitian yang dilakukan oleh Purwanti (2009) bertujuan untuk mengungkapkan persamaan dan perbedaan antara novel Saman dan Larung serta mengungkapkan perspektif gender dan nilai feminisme dalam novel Saman dan Larung karya Ayu Utami.

Berdasarkan latar belakang tersebut, peneliti melakukan penelitian berjudul "Realisme Magis dalam Novel Simple Miracles Doa dan Arwah Karya Ayu Utami" dengan fokus penelitian mengungkapkan bagaimana realisme magis yang ternarasikan dalam novel serta menjelaskan wujud konteks sosial yang melatarbelakangi munculnya narasi realisme magis dalam novel tersebut. Hal itu disebabkan karya realisme magis selalu terkait dengan konteks sosial yang melatarbelakangi kemunculannya.

\section{KAJIAN PUSTAKA}

Teori yang digunakan untuk menganalisis objek penelitian adalah teori realisme magis Wendi B. Faris. Menurut Faris (1995), realisme magis merupakan suatu paham yang menghadirkan kembali segala citra dan pengertian yang bersifat magis, mistis, ataupun "irrasional" yang bersumber dari karya-karya mitologis, dongeng, legenda yang hidup secara tradisional dalam kesusastraan modern.

Menurut Faris (2004) untuk mengetahui bagaimana suatu teks terlihat sebagai karya realisme magis bukan hanya melihat adanya hal magis yang diangkat berdasarkan mitos serta legenda dari kebudayaan tertentu, tetapi juga adanya lima karakteristik fiksi realisme magis yang nampak di dalam teksnya. Faris menambahkan kelima karakteristik itu nantinya akan memperlihatkan bagaimana model narasi realisme magis yang terlihat pada suatu teks sastra.

Wendy B. Faris (2004) menjelaskan bahwa realisme magis memiliki lima karakterisik, yakni irreducible element (elemen yang tak tereduksi yang menyangkut hal-hal magis), phenomenal world (dunia yang fenomenal yang mencegah hal magis menuju dunia fantasi), unsettling doubt (keraguan yang tak terselesaikan yang terjadi ketika akan mengkooptasi teks ke dalam elemen yang tak tereduksi), merging realms (alam yang bercampur menyatunya hal magis dan real), dan disruption of time, space, and identity (disrupsi atau pengacauan atas waktu, ruang, dan identitas sakral menuju waktu, ruang, dan identitas rutin).

Faris (2004:25), menambahkan kelima karakteristik yang muncul dari teks realisme magis akan mempermudah pembaca melihat bagaimana cara pengarang memperlihatkan realisme magis yang ternarasikan dalam teks yang dibuatnya. Sebab antara pengarang yang satu dengan pengarang yang lain memiliki perbedaan ketika menyajikan sesuatu hal magis dalam tulisannya. Terkait dengan teks realisme magis yang mengangkat hal magis yang bersumber dari kebudayaan tertentu, Faris mengungkapkan, setelah diketahui bagaimana narasi realisme magis dalam suatu teks, selanjutnya seorang pembaca harus mengaitkan isi teks dengan hal di luar teks terkait dengan konteks sosial budaya di mana karya tersebut tercipta. Hal tersebut disebabkan setiap fiksi realisme magis selalu mengkomunikasikan atau menghadirkan isu-isu sosial tertentu (2004:10). Bukan hanya itu, ketika seorang pembaca mengaitkan isi teks dengan konteks sosial budaya di luar teks maka akan diketahui

Jurnal Lakon: Kajian Sastra dan Budaya e-ISSN: 2527-4899; p-ISSN 2252-8954 
hal-hal yang melatarbelakangi kemunculan teks tersebut.

\section{METODE PENELITIAN}

Penelitian ini termasuk penelitian kualitatif. Penelitian kualititaf yaitu penelitian yang menginterpretasikan suatu permasalahan yang diangkat seorang peneliti. Dalam proyek penelitian kualitatif permasalahan yang diinterpretasi mencakup hal-hal yang sifatnya luas atau mencakup perspektif pada semua aspek (Creswell, 2007:23-24). Dengan kata lain, yang akan diinterpretasikan dalam penelitian ini adalah realisme magis yang ternarasikan dalam novel "Simple Miracles Doa dan Arwah" karya Ayu Utami. Menurut Crewell (2012:16), salah satu karakteristik utama penelitian kualitatif adalah menganalisis data untuk dideskripsi dengan menggunakan analisis teks dan menafsirkannya.

Pada penelitian ini sumber data yang digunakan yakni berupa novel "Simple Miracles Doa dan Arwah" karya Ayu Utami. Peneliti memilih sumber data novel "Simple Miracles Doa dan Arwah". Data yang diambil untuk bahan penelitian ini berupa teks-teks yang ternarasikan dalam sumber data yakni, novel "Simple Miracles Doa dan Arwah" karya Ayu Utami yang dapat mengungkapkan jawaban pertanyaan rumusan masalah pertama yakni mengenai realisme magis yang ternarasikan dalam novel, kemudian teks-teks penunjang yang berada di dalam sumber data selanjutnya yang diperoleh dari buku-buku atau dokumen untuk menjawab pertanyaan rumusan masalah nomor dua, yakni mengenai konteks sosial budaya yang melatari kemunculan narasi realisme magis dalam novel.
Teknik pengumpulan data dalam penelitian ini menggunakan teknik studi pustaka (library research), yakni membaca secara mendalam novel serta menandai dan mengidentifikasi data yang terkait dengan permasalahan penelitian yang diangkat. Teknik ini digunakan karena sumber data bersifat tertulis.

Data yang terkumpul selanjutnya dianalisis dengan menggunakan tekstual analisis atau analisis teks (Gadamer dalam Selden, 1991:122). Analisis teks bertujuan untuk menginterpretasikan data temuan dengan menggunakan teori yang terkait, dalam hal ini realisme magis Wendy B. Faris (2004).

\section{HASIL DAN PEMBAHASAN}

\section{Narasi Realisme Magis dalam Novel Simple Miracles Doa dan Arwah Karya Ayu Utami}

Sesuai cara kerja teori realisme magis yang telah dijelaskan pada bab II, pada bab ini dilakukan analisis dengan cara memanfaatkan kelima karakteristik realisme magis ke dalam teks SMDA. Hal ini dilakukan untuk mengetahui kadar realisme magis dalam teks serta mengungkapkan bagaimana realisme magis yang ternarasikan dalam novel SMDA Karya Ayu Utami.

\section{Irreducible Element (Elemen yang Tak Tereduksi)}

Hal-hal yang terdeteksi sebagai irreducible element dalam novel yaitu elemen magis sebagai elemen yang tidak biasa yang dianggap tidak sesuai logika empirisme Barat selama ini. Elemen magis dalam teks novel Simple Miracles Doa dan Arwah yang diadopsi dari sistem kepercayaan masyarakat Jawa, elemen 
magis tersebut dapat digolongkan ke dalam empat kelompok utama yaitu berdasarkan objek magis (tempat yang terkategori magis (tempat munculnya makhluk halus serta tempat terjadinya peristiwa magis), makhluk halus (memedi dan arwah penasaran), bunyi magis (suara tertawaan memedi)), karakter tokoh, peristiwa magis, dan kepercayaan atau mitos yang di luar nalar.

Objek magis dibatasi pada empat hal yaitu tempat, makhluk halus, benda, dan bunyi yang memiliki sifat irrasional. Karakter tokoh yang akan diulas pada penelitian ini hanya berkaitan pada tokoh yang memiliki kekuatan di luar nalar manusia, yakni Bonifacius yang memiliki kemampuan berkomunikasi dengan arwah. Peristiwa magis dalam penelitian ini berkaitan dengan peristiwa-peristiwa yang termasuk kategori irrasional atau di luar nalar manusia serta masih memiliki relasi dengan objek magis dan tokoh-tokoh yang mengalami peristiwa magis, seperti peristiwa pertama kali Bonifacius melihat hantu, melihat arwah Kakek ketika misa kematian, dan lain-lain seperti terlihat pada kutipan berikut.

"Tiba-tiba ia menunjuk ke depan dan berkata. "A-um!"

"Ketika ia mulai bisa merangkai kata dalam kalimat, ia pun berkata: " $A$ - um! Tu a-um!" Tangannya menunjuk ke depan. Dahinya berkerutdan matanya melirik nyaris putih. A-um. Itu A-um.

"Kami terdiam."

"Cicilia mengangguk kepadaku." "Tak berapa lama kemudian orang- orang berkata bahwa anak itu bisa melihat makhluk halus." (Utami, 2014:25-26)
Kategori keempat yang tergolong hal-hal magis adalah kepercayaan atau mitos yang dianggap tidak rasional. Dalam novel SMDA kepercayaan yang berada di luar nalar seperti, malam Jumat Kliwon dan malam Selasa Kliwon (munculnya makhluk halus), orang yang memiliki ageman (ilmu jati) akan sulit meninggal, keberadaan arwah seseorang yang telah meninggal di rumah selama 40 hari, adanya konsep sedulur papat lima pancer.

\section{Phenomenal World (Dunia yang Fenomenal)}

Dunia fenomenal ini merupakan bagian yang real atau nyata dari realisme magis yang mencegah fiksi tersebut menjadi bentuk fiksi fantasi yang dapat melambung meninggalkan alam real secara total. Dunia fenomenal yang menjadi latar bagi unsur-unsur magis tersebut terbagi ke dalam dua jenis, yaitu: (1) kenyataan (yang real) di dalam teks dan (2) kenyataan yang berlandaskan pada sejarah.

Dunia fenomenal yang nyata dalam teks dijelaskan sesuai pengelompokkan; objek dunia fenomenal (tempat, benda, waktu), karakter tokoh (yang berkaitan dengan profesi tokoh); serta peristiwa dunia fenomenal itu sendiri. Dalam karakteristik dunia fenomenal, hal-hal yang bersifat real ini hadir untuk membuat yang magis tetap berada di dunia nyata tidak melambung ke dunia fantasi (masuk ke alam lain) seperti karya fiksi fantasi. Seperti halnya kehadiran dunia fenomenal yang berlandaskan sejarah (peristiwa terbunuhnya Romo Sanjoyo di Muntilan dan peristiwa asal-usul Lourdes dijadikan tempat ziarah). 
Unsettling Doubt (Keraguan yang Meresahkan)

Ada tiga variasi keraguan (hesitation) berdasarkan paparan Faris (2004:17), yakni keraguan yang dipicu oleh teks, keraguan yang dipicu oleh properti objek, dan keraguan yang disebabkan oleh latar budaya si pembaca itu sendiri. Akibat adanya keragu-raguan yang meresahkan juga dapat mengaburkan the irreducible element yang konsekuensinya tidak selalu mudah dilihat sebagaimana demikian. Pada bagian ini hanya akan dibahas keraguan yang dipicu oleh teks dan properti objek sebab peneliti berasal dari budaya yang sama dengan konteks sosial di dalam narasi SMDA.

Pertama, keraguan yang dipicu oleh teks. Kedekatan antara teks yang mengandung elemen yang tak tereduksi dengan teks yang mengandung dunia fenomenal inilah yang menjadikan adanya keragu- raguan yang meresahkan. Keraguan yang meresahkan dalam narasi SMDA dilihat dari tiga kategori yaitu berdasarkan objek, karakter, dan peristiwa. Tiga kategori ini akan diuji hubungan logis antara setiap elemen yang tidak tereduksi itu sebelum menyimpulkan bahwa narasi tersebut benar-benar tidak dapat direduksi. Misalnya, pada contoh analisis berikut ini.

Keraguan yang meresahkan dalam teks novel SMDA kategori benda atau properti objek yang digunakan antara lain terjadi pada peristiwa yang berhubungan dengan sofa pijat milik tokoh Ayah dan televisi yang ada di kamar Ibu. Sofa pijat memunculkan keraguan yang meresahkan pembaca karena dalam teks diceritakan bahwa sesuatu pada layar monitor pada sofa pijat menyala sendiri ketika narator dan pasangan hidupnya yang bernama Rik menginap di rumah Ibu.

Pembaca mengalami keraguan karena teks yang ada pada novel SMDA memperlihatkan narasi yang bercerita bahwa narator dan Rik memiliki pertanyaan pada diri mereka sendiri mengenai siapa sebelumnya yang memakai sofa pijat milik almarhum tokoh Ayah itu. Pertanyaan itu muncul karena yang menghuni rumah tokoh Ibu itu ada beberapa orang dan para asisten rumah tangga serta suster yang merawat tokoh Ibu pun termasuk di dalamnya. Awalnya, pembaca (peneliti) merasa bahwa ini bukan termasuk elemen yang tak tereduksi, namun pemikiran peneliti dibantah pada narasi lain yang menjelaskan bahwa sejak si tokoh Ibu sakit tidak ada yang memakai sofa pijat tersebut yang terlihat pada kutipan berikut.

"Tapi aku dan Rik tak tahu apakah monitor penyetelnya tadi mati atau hidup. Rasanya, dari kemarin tidak ada yang memakainya. Rasanya, sejak Ibu sakit tidak ada yang memanfaatkannya. Aku dan Rik berpandang-pandangan. Adakah benda itu tiba-tiba menyala, seolah ada yang mau memakainya? Atau tadi kami tidak mengamati?" (Utami, 2014:142)

Hal-hal yang berkaitan dengan teks dan properti itulah yang membuat peneliti mengalami keraguan yang meresahkan. Namun pada akhirnya keraguan peneliti hilang serta dapat menentukan bahwa sofa pijat termasuk benda magis sebab terdapat narasi pendukung yang menjelaskan bahwa menyalanya sofa pijat itu terjadi pada Selasa Kliwon yang selama ini dipercaya sebagai malam keramat di mana roh orang yang telah meninggal akan berkunjung ke 
rumah untuk menemui keluarganya. Dalam narasi diperlihatkan sofa pijat sebagai perantara magis. Kemantapan peneliti memilih sofa pijat sebagai benda magis karena terdapat narasi yang menjelaskan bahwa Rik, narator, serta tokoh Ibu mempercayai sofa pijat itu menyala sendiri karena sedang digunakan oleh arwah tokoh Ayah.

\section{Merging Realms (Alam yang Bercampur)}

Pada karakteristik Merging Realms atau alam yang bercampur, realisme magis menggabungkan atau meleburkan dunia magis (yang berkaitan dengan kepercayaan tradisional) dan dunia real (modern) (Faris, 2004:21). Pada karakteristik keempat ini juga dijelaskan sesuai pengelompokkan objek, karakter tokoh, dan peristiwa. Peleburan dua dunia ditinjau dari segi objek dibatasi dalam tiga bagian yaitu berdasarkan kategori benda, tempat, dan waktu yang diungkap penggabungan antara yang real dan yang magis, seperti halnya dari segi karakter tokoh dan peristiwanya. Contoh analisisnya seperti berikut.

"Ia ngobrol dengan seorang anak lelaki. Anak itu bercerita macam-macam, tentang guru-guru, permainan, dan pelajaran di sekolah ini. ia memang bukan bagian dari kelas ini. Tetapi ia suka datang dan pergi begitu saja. "Kamu ngomong sendiri lagi." (Utami, 2014:31-32)

Kutipan narasi tersebut menceritakan bahwa Bonifacius memiliki teman tak terlihat di sekolahnya dan sering mengajaknya berbicara, sehingga ia sering ditegur gurunya karena dianggap suka berbicara sendiri. Kutipan tersebut memperlihatkan karakteristik merging realms. Hal itu disebabkan sekolah yang seharusnya digunakan manusia sebagai tempat menuntut ilmu tetapi juga diperlihatkan sebagai tempat singgah arwah penasaran. Dari kutipan narasi tersebut dapat diketahui bahwa dalam proses penyatuan atau pemindahan antardunia tersebut (dunia real dan dunia magis), realisme magis memburamkan batas antara yang fakta dan magis dengan cara menghilangkan mediasi antara kenyataan yang berbeda. Seperti yang terlihat pada kutipan tersebut, di satu sisi sekolah sebagai tempat real atau nyata sebagai tempat menuntut ilmu, namun di sisi lain sekolah dalam kutipan tersebut juga digambarkan sebagai tempat singgah arwah penasaran.

\section{Disruption of Time, Space, and Identity (Disrupsi Waktu, Ruang, dan Identitas)}

\section{Disruption of Time (Gangguan atau Pengacauan terhadap Waktu)}

Adanya gangguan atas waktu (disruption of time) dalam karya fiksi realisme magis dapat memunculkan waktu baru (waktu rutin) sebagai pengganti waktu yang sakral (Farßs, cedo4:23)it\$BG\& $k$ gemuk. dari adanya karakteristik disruption of time dalam novel SMDA adalah adanya waktu baru dalam konteks kemunculan hantu atau makhluk halus. Dalam konteks sakral makhlus halus selalu muncul malam hari, tetapi dalam novel SMDA makhlus halus tidak hanya muncul pagi bahkan siang hari. Ini merupakan ciri karya realisme magis, di mana waktu sakral dikacaukan sehingga mengganti waktu sakral menjadi waktu rutin.

Adanya waktu baru dalam kemunculan makhluk halus terlihat pada peristiwa ketika teman sekolah Bonifacius meninggal serta misa 40 harian tokoh Ibu.

Jurnal Lakon: Kajian Sastra dan Budaya 
Pada peristiwa kematian teman Bonifacius yang meninggal karena kecelakaan arwahnya muncul pada pagi hari seperti yang terlihat pada kutipan narasi berikut.

"Suatu hari dua kawan sekolahnya mengalami kecelakaan mobil. Yang seorang meninggal dunia. Murid-murid kelas melayat bersama-sama. Tapi, esok- esok harinya Bonifacius melihat anak yang sudah meninggal itu datang ke sekolah." (Utami, 2014:33)

Berdasarkan kutipan tersebut, diketahui bahwa terjadi pengacauan waktu dalam konteks kemunculan makhluk halus. Sesuai waktu sakral makhluk halus atau hantu selalu muncul malam hari. Namun pada novel SMDA, makhluk halus dimunculkan pada pagi hari pada waktu rutin bukan lagi waktu sakral.

\section{Disruption of Space (Gangguan atau Pengacauan terhadap Ruang)}

Pada bagian pengacauan ruang narasi realisme magis juga dapat memunculkan ruang baru yang tidak homogen. Ruang baru yang dimaksud adalah ruang yang ada pada rutinitas sehari-hari bukan ruang khusus yang berkaitan dengan kesakralan. Dalam novel SMDA adanya karakteristik disruption of space adalah adanya ruang baru mengenai kemunculan atau tempat berkeliaran makhluk halus.

Dalam konteks ruang sakral makhlus halus selalu berada pada tempat- tempat keramat, seperti pernyataan Geertz (1989). Tetapi dalam novel SMDA makhlus halus dihadirkan berada di ruang-ruang publik seperti sekolah, rumah, dan jalan raya. Ini merupakan ciri karya realisme magis, di mana ruang sakral dikacaukan sehingga mengganti ruang sakral menjadi ruang rutin.

Hal tersebut diperlihatkan melalui peristiwa yang menceritakan bahwa arwah teman Bonifacius yang mengalami kecelakaan tempo hari datang ke sekolah. Padahal sekolah merupakan ruang publik sebagai tempat mengajar dan belajar. Dalam ruang sakral arwah tidak muncul di sekolah tetapi karena karya SMDA menghadirkan hal-hal bercitra tradisional ke modern, maka memunculkan ruang baru dalam kemunculan hantu. Dalam novel SMDA ruang baru tempat munculnya hantu juga ada di ruang tamu yang selama ini merupakan sebuah ruangan yang ada di rumah digunakan untuk menerima tamu. Diceritakan bahwa tokoh Bonifacius melihat tujuh kuntilanak di ruang tamunya.

Selain sekolah dan ruang tamu, hantu juga dimunculkan di jalan raya yang merupakan tempat lalu-lalang kendaraan. Jalan raya bukanlah tempat yang menakutkan dalam kacamata hal- hal yang berbau mistis. Namun novel ini menghadirkan tempat baru dengan memperlihatkan bahwa makhluk halus baik arwah atau hantu itu ada di manamana di tempat-tempat yang digunakan manusia dalam kehidupan sehari-hari.

"Ia khawatir bisa menabrak orang sungguhan lantaran mengira hantu. Tak ada waktu untuk mengamati apakah yang berdiri di tengah jalan itu manusia atau makhluk halus." (Utami, 2014:155) 


\section{Disruption of Identity (Gangguan atau Pengacauan terhadap Indentitas)}

Disruptions of identity (gangguan atau pengacauan terhadap identitas) pada narasi realisme magis dapat memunculkan identitas yang baru yang tidak homogen. Realisme magis mengaktualisasi identitas menjadi multiplisitas personal (Faris, 2004:26). Identitas menurut Faris (2004:26-27), yaitu identitas yang mendekonstruksi individualitas dengan memberi kesadaran pada pembaca bahwa identitas apapun adalah konstruksi. Selain itu, identitas tersebut sekaligus melawan secara terbuka konsep yang telah tertanam, baik dalam fiksi maupun sejarah.

Gangguan identitas dalam novel SMDA berangkat dari adanya karakter multiple identity, yakni karakter yang terkadang memiliki lebih dari satu identitas yang terkonstruksi dalam diri tokoh sehingga tidak jarang membuat pembaca sulit memahami karakter tokoh dalam teks realisme magis karena dianggap tidak jelas.

Gangguan identitas terlihat pada karakter Bonifacius, di satu sisi identitasnya merupakan anak sekolah tetapi di sisi lain si anak sekolah yang seharusnya memiliki sifat normal layaknya pelajar, namun di sisi lain si anak sekolah ini merupakan anak indigo yang dapat melihat makhluk halus, serta merupakan dukun yang ahli menemukan letak di mana barang hilang. Identitas Bonifacius tidaklah homogen tetapi multiplisitas karena Bonifacius yang merupakan satu karakter memiliki lebih dari satu identitas, yakni sebagai pelajar, anak indigo, dan dukun. Sastra realisme magis seakan memperlihatkan identitas baru bahwa seseorang yang dapat berkomunikasi dengan makhluk halus serta melacak benda berharga yang hilang bukan hanya seorang dukun (identitas sakral), tetapi di novel ini diperlihatkan justru anak sekolah biasa yang mempunyai kekuatan tersebut. Penjelasan tersebut dipertegas oleh kutipan berikut.

"Sepuluh tahun kemudian Bonifacius telah jadi murid SMA Pangudi Luhur di Kebayoran Baru. Ia sudah jejaka belia. Ia dikenal sebagai anak yang berbeda; teman-temannya tahu ia melihat yang tidak dilihat orang banyak." (Utami, 2014:33)

(...)

"Di pihak lain lain, banyak orang di Indonesia sangat suka mistik dan dunia gaib. Itu juga terjadi dalam keluarga kami. Kami suka memperlakukan dia seperti dukun. Di kalangan kerabat ia mulai dikenal sebagai ahli menemukan barang hilang." (Utami, 2014:94)

\section{Kadar Realisme Magis dalam Novel Simple Miracles Doa dan Arwah}

Pada novel SMDA, semua karakteristik karya sastra realisme magis hadir serta terindentifikasi dengan jelas sehingga dapat dikatakan bahwa kadar kemagisannya sangat kuat. Hal tersebut juga disebabkan semua tokoh yang ada di dalam novel ini percaya akan hal-hal magis yang terkait dengan kepercayaan atau mitos-mitos yang ada di Jawa serta narasi SMDA sarat akan kelima karakteristik realisme magis.

\section{Narasi Realisme Magis dalam Novel Simple Miracles Doa dan Arwah Karya Ayu Utami}

Narasi realisme magis pada novel SMDA karya Ayu Utami (yang mengangkat hal magis berkaitan dengan mitos adanya makhluk halus) ini sarat dengan 
karakteristik realisme magis Faris yang juga memperlihatkan eksistensi mitos/kepercayaan tersebut di era modern seperti sekarang. Dalam menghadirkan hal magis pada narasi realisme magisnya, Ayu Utami tidak sekadar memperlihatkan eksistensi mitos/kepercayaan di era modern, tetapi juga bertugas mengukuhkan suatu kepercayaan mengenai mitos tertentu bahkan merombaknya.

Cara pengarang (Ayu Utami)
$\begin{array}{llr}\text { mengukuhkan mitos tersebut } \\ \text { dengan } & \text { memperlihatkan } & \text { atau }\end{array}$
memperkenalkan kepada pembaca (baik pembaca dari Jawa maupun luar Jawa) inilah karakteristik orang Jawa yang menganut budaya Jawa serta mengajak para pembaca yang berasal dari Jawa untuk melestarikan tradisi tersebut. Pada novelnya, pengarang merombak sesuatu yang berbau sakral menjadi sesuatu yang berbau rutin yang terkait dengan kemunculan makhluk halus bukan hanya malam hari di tempat yang angker, tetapi setiap saat di mana saja (baik di tempat angker, rumah, maupun ruang publik) dan kapan saja tidak lagi terikat dengan waktuwaktu keramat.

\section{Konteks Sosial Budaya yang Melatarbelakangi Munculnya Narasi Realisme Magis Dalam Novel Simple Miracles Doa dan Arwah Karya Ayu Utami}

Latar belakang munculnya narasi SMDA didukung oleh kebudayaan Jawa yang sampai saat ini masih eksis. Eksistensi kebudayaan Jawa tersebut selain dengan didukung orang-orang tua yang masih menanamkan tradisi-tradisi Jawa pada generasi muda juga karena didukung pemerintah (baik presiden maupun elit politik) yang didominasi oleh orang Jawa yang selama kepemimpinannya memperlihatkan bagaimana sikap hidup orang Jawa, tradisi Jawa (misalnya pada acara pernikahan putra sulung Presiden Jokowi yang menggunakan adat Jawa), serta dominasi budaya Jawa terhadap pertelevisian nasional. Di TV banyak ditayangkan sinetron atau drama yang kebanyakan mengangkat budaya Jawa, jika itu film horor maka yang diangkat pasti hantu-hantu yang melegenda di tanah Jawa. Sehingga membuat hal-hal yang berbau tradisional tersebut kembali populer.

$\begin{array}{clc}\text { Motif } & \text { di balik munculnya novel } \\ \text { bergenre } & \text { realisme } & \text { magis }\end{array}$ menghadirkan mitos atau kepercayaan yang berasal dari masa lampau ke masa kini, bukan hanya dihadirkan untuk dijadikan sebagai dokumen sosial budaya yang mencatat kenyataan budaya suatu masyarakat pada masa tertentu-seperti yang dijelaskan oleh Junus (1986), bahwa fungsi karya sastra juga sebagai dokumen sosial budaya yang menjelaskan budaya atau keadaan masyarakat pada masa tertentu-tetapi juga bermaksud memperlihatkan bahwa semodern apapun manusia tetap tak dapat terpisahkan dari kepercayaan-kepercayaan magis tersebut. Manusia akan tetap lari kepada hal-hal mistis atau mempercayai mitos jika ilmu pengetahuan tidak lagi dapat memberikan kepuasan ketika memperlihatkan hasil pemecahan masalah.

\section{Isu-Isu Sosial}

Isu sosial yang pertama adalah isu mengenai kesukaan orang Jawa pada halhal mistik. Berdasarkan pembahasan secara mendalam mengenai kelima karakteristik realisme magis dalam novel SMDA, terdapat hal menarik yang ditemukan peneliti, yaitu isu mengenai 
kesukaan orang Jawa terhadap hal-hal mistik. Dunia mistik yang disukai orang Jawa selalu berkaitan dengan makhluk halus. Hal tersebut terlihat dari tiap narasi yang didominasi penceritaan mengenai makhluk-makhluk halus yang dipercaya orang Jawa yang berasal dari mitos atau kepercayaan tradisional.

\section{Novel SMDA juga}

memperlihatkan isu mengenai akulturasi agama di Jawa dengan budaya Jawa. Hal ini memperlihatkan bahwa agama-agama yang berkembang di Jawa menampilkan keunikan tersendiri dengan agama- agama yang berkembang di luar Jawa. Selain itu juga diperlihatkan bahwa budaya Jawa lebih mudah atau lebih fleksibel menerima agama-agama baru yang masuk karena dasarnya ciri khas masyarakat Jawa adalah percaya pada Tuhan yang menjadi Sangkan Paraning Dumadi. Namun dalam menjalankan agamanya orang Jawa tetap tidak meninggalkan kesan budaya Jawanya.

Hasil analisis mendalam pada karya realisme magis (novel SMDA) yang dilakukan peneliti ini juga menghasilkan beberapa makna. Makna yang diperoleh antara lain: (1) orang Jawa akan selalu percaya pada hal-hal mistis yang berkaitan dengan makhluk halus; (2) di Jawa, dukun dan makhluk halus adalah alternatif kedua untuk mewujudkan cita-cita; (3) identitas dukun identik dengan seorang yang memiliki kemampuan melihat dan berkomunikasi dengan makhluk halus; (4) adanya kepercayaan bahwa makhluk halus itu ada di mana-mana; (5) orang Jawa percaya bahwa setiap orang meninggal akan menjadi roh yang tetap hidup di sekeliling mereka; (6) orang ateis jarang ditemui di Jawa; dan (7) Agama-agama yang ada di Jawa selalu menyesuaikan diri dengan kebudayaan Jawa.

\section{KESIMPULAN}

Berdasarkan hasil analisis mendalam sesuai permasalahan yang diangkat pada novel SMDA dapat diambil simpulan bahwa narasi realisme magis pada novel SMDA karya Ayu Utami (yang mengangkat hal magis berkaitan dengan mitos adanya makhluk halus) ini sarat dengan karakteristik realisme magis Faris yang juga memperlihatkan eksistensi mitos/kepercayaan tersebut di era modern seperti sekarang. Dalam menghadirkan hal magis pada narasi realisme magisnya, Ayu Utami tidak sekadar memperlihatkan eksistensi mitos/kepercayaan di era modern, tetapi juga bertugas mengukuhkan suatu kepercayaan mengenai mitos di Jawa bahkan merombaknya.

Hal-hal yang melatarbelakangi narasi SMDA didukung oleh kebudayaan Jawa yang sampai saat ini masih eksis serta kembali populernya hal-hal yang berbau tradisional dalam era modern ini. Eksistensi kebudayaan Jawa karena adanya dukungan orang- orang tua yang masih menanamkan tradisi-tradisi Jawa pada generasi muda serta pemerintah (baik presiden maupun elit politik) yang didominasi oleh orang Jawa yang selama kepemimpinannya memperlihatkan bagaimana sikap hidup orang Jawa, tradisi Jawa Kepopuleran halhal yang berbau tradisional (yang berkaitan dengan mitos makhluk halus, legenda, maupun takhyu di kebudayaan Jawa) dalam era modern ini didukung oleh media massa misalnya televisi.

Narasi realisme magis yang ada di dalam novel SMDA memperlihatkan dua isu sosial. Isu sosial yang pertama adalah isu mengenai kesukaan orang Jawa pada halhal mistik yang berkaitan dengan makhluk halus. Isu sosial yang kedua mengenai

Jurnal Lakon: Kajian Sastra dan Budaya 
akulturasi budaya Jawa dengan agamaagama di Jawa.

Hasil analisis mendalam pada karya realisme magis (novel SMDA) yang dilakukan peneliti ini juga menghasilkan tujuh makna antara lain: (1) orang Jawa akan selalu percaya pada hal-hal mistis yang berkaitan dengan makhluk halus; (2) di Jawa, dukun dan makhluk halus adalah alternatif kedua untuk mewujudkan citacita; (3) identitas dukun identik dengan seorang yang memiliki kemampuan melihat dan berkomunikasi dengan makhluk halus; (4) adanya kepercayaan bahwa makhluk halus itu ada di mana-mana; (5) orang Jawa percaya bahwa setiap orang meninggal akan menjadi roh yang tetap hidup di sekeliling mereka; (6) orang ateis jarang ditemui di Jawa; dan (7) Agamaagama yang ada di Jawa selalu menyesuaikan diri dengan kebudayaan Jawa.

\section{SARAN}

Berdasarkan hasil analisis mengenai narasi realisme magis serta konteks sosial budaya yang melatabelakangi munculnya narasi realisme magis dalam novel SMDA karya Ayu Utami, peneliti dapat memberi saran untuk penelitian selanjutnya yang sejenis. Saran yang diberikan peneliti adalah alangkah lebih baiknya untuk penelitian selanjutnya seorang peneliti tidak hanya membahas atau menganalisis teks realisme magis yang mengangkat cerita dengan konteks sosial budaya sesuai budaya peneliti, tetapi juga mengangkat teks realisme yang konteks sosial budayanya berbeda dengan peneliti. Agar dalam karakteristik unsettling doubts (keraguan yang meresahkan), ditemukan keraguan yang berdasar pada kebudayaan yang berbeda bukan hanya keraguan yang dipicu oleh teks serta properti objek seperti dalam penelitian ini.

\section{DAFTAR PUST AKA}

Alex, Supranoto. (2003). Menulis Sejarah, Membangkitkan Tokoh dari Kubur:

Realisme Magis dalam Novel Cantik

Itu Luka. Kompas edisi 30 November 2003.

Creswell, John W. (2007). Qualitative Inquiry \& Research Design (Choosing Among Five Approaches). Second Edition. Thousand Oaks, London, New Delhi: SAGE Publications. . (2012). Educational Research (Planning, Conducting and Evaluating Quantitative and Qualitative Research). Fourth Edition. Boston, Columbus, Indianapolis, New York, London: PEARSON.

Faris, Wendy B. (2004). Ordinary

Enchantments: Magical Realism and the Remystification of Narrative. Nashville: Vanderbilt University Press.

Ferdiyanto, Niko. (2014). Realisme Magis dalam Novel Beloved Karya Toni Morrison. Tesis tidak diedarkan. Yogyakarta: Universitas Gadjah Mada.

Geertz, Clifford. (1989). Abangan, Santri, Priyayi dalam Masyarakat Jawa. Jakarta: Pustaka Jaya.

Hardjowirogo, Marbangun. (1984). Manusia Jawa. Jakarta: Idayu Press.

Junus, Umar. (1986). Sosiologi Sastra:

Persoalan Teori dan Metode.

Kualalumpur: Dewan Bahasa dan

Pustaka Kementerian Pelajaran Malaysia.

Kadir, Burhan. (2014). Kadar Realisme Magis dalam Novel Perempuan Poppo Karya Dul Abdul Rahman.

Jurnal Lakon: Kajian Sastra dan Budaya e-ISSN: 2527-4899; p-ISSN 2252-8954 
Tesis tidak diedarkan. Yogyakarta:

Universitas Gadjah Mada.

Purwanti, Yuni. (2009). Novel Saman dan

Larung Karya Ayu Utami dalam

Perspektif Gender. Tesis tidak

diedarkan. Surakarta: Universitas

Sebelas Maret Surakarta.

Selden, Rahman. (1991). Panduan

Membaca Teori Sastra Masa Kini.

Yogyakarta: Gadjah Mada

University Press.

Semi, Atar. (1989). Kritik Sastra. Bandung:

Angkasa.

Sudiantara, Y.. (1998). Nilai-nilai Hidup

dalam Masyarakat Jawa. Semarang:

Universitas Khatolik

Soegijapranata.

Setyodarmodjo, dkk (Tim Lembaga

Javanologi Surabaya). (2007).

Menggali Filsafat dan Budaya Jawa.

Jakarta: Prestasi Pustaka Publisher.

Tom, Jennifer Lynne. (1999). Magical

Realism, Freedom, and Control in

Garcia Marquez, Millhauser, and

Winterson. Master's Theses and

graduate Research. USA: San Jose

Satet University.

Utami, Ayu. (2014). Simple Miracles Doa

dan Arwah. Jakarta: Kepustakaan

Populer Gramedia.

Zamora, Louis Parkinson and Faris Wendy

B (ed.). (1995). Magical Realism

(Theory, History, Community).

Durham dan London: Duke

University Press. 